\title{
СОВРЕМЕННЫЕ ОСОБЕННОСТИ РАЗВИТИЯ БАНКОВСКОГО СЕКТОРА АЗЕРБАЙДЖАНА
}

\author{
(C) 2020 Мамедов Захид Фаррух \\ доктор экономических наук, профессор \\ директор департамента «Организация и управление научной деятельностью» \\ Азербайджанский государственный экономический университет (UNEC), Азербайджан, Баку \\ профессор университета «IŞIK», Турецкая Республика \\ E-mail: zahid.mammadov@unec.edu.az \\ (c) 2020 Валиев Эльхан Нариман оглы \\ Ph. D. \\ Азербайджанский государственный экономический университет (UNEC), Азербайджан, Баку
}

\section{(c) 2020 Вейсов Емин Назим оглы}

магистрант

Белорусский государственный экономический университет, Беларусь, Минск

Следует констатировать, что проблемы, связанные с реформированием, устойчивостью и повышением эффективной деятельности банковского сектора Азербайджана в условиях возрастающей конкуренции не нашли должного отражения в исследованиях азербайджанских ученыхэкономистов.

В статье показаны этапы формирования и развития банковского сектора Азербайджана, а также изучены особенности и тенденции развития банковского сектора за последнее десятилетие. Автор, исследовав результаты, полученные в развитии банковского сектора и проблемы, возникающие в этой области, дает свои рекомендации и выдвигает идеи по развитию этого сектора.

Ключевые слова: Банковский сектор Азербайджана; финансовый рынок Азербайджана; особенности и тенденции развития банковского сектора; реформирования банковской сферы; капитализация банковского сектора.

\section{Введение}

Современные глобальные вызовы прямо и косвенно воздействуют на самые разнообразные сферы экономики. Безусловно, общие характеристики азербайджанской экономики воздействуют на уровень ее высокой чувствительности в плане внешних шоков, что, в свою очередь, безусловно, оказывает влияние и на банковскую систему. В то же время возникающие факторы воздействия, а также быстрая сменяемость внутренней и внешней конъюнктуры макроэкономики создают определенные предпосылки для дальнейших исследований проблем, связанных с развитием и повышением устойчивости азербайджанского банковского сектора в период новых вызовов.

Особую значимость в рамках рассматриваемого вопроса представляют проблемы, оказывающих негативное влияние на совершенствование деятельности азербайджанских банков, а также на установку определяющих направлений и способов их решения. Объективная необходимость комплексной модернизации банковского сектора Азербайджана обусловила принятие новых законов.

Этапы развития банковского сектора Азербайджана

По мнению проф. Захид Мамедова, «что с начала 1990-х годов банковская система Азербайджана прошла в своем развитии три этапа:

1. 1990-1992 гг.- период формирования национальной банковской системы;

2. 1992-1994 гг.- период стремительного роста количества коммерческих банков в условиях гиперинфляции;

3. 1995-2003 гг.- оптимизация и реструктуризация банковской системы в условиях макроэкономической стабилизации. С этого момента и начался качественно новый - третий этап развития банковской системы Азербайджана» $[1,71]$.

Авторы статьи - «Антикризисная полити- 
ка в банковской сфере Российской федерации, Азербайджана и Турции: сравнительный анализ» (исследователи из России, Турции и Азербайджана), отмечают, что - позитивный момент развития банковской системы Азербайджана состоял в следующем: «Быстрое укрепление маната подтолкнуло процесс «девалютизации» сбережений населения, что поддержало рост ресурсной базы банков и удлинение сроков привлекаемых средств; Рост показателей внешней платежеспособности Азербайджана в сочетании с либерализацией валютного законодательства и укреплением маната стимулировали приток капиталов, резко повысили привлекательность банковского сектора для иностранных инвесторов; Снижение уровня инфляции, рост конкуренции, обусловленный открытием ключевых сегментов национального финансового рынка, дали импульс быстрому развитию новых перспективных видов финансовых услуг» $[2,6]$.

В связи с объективной необходимостью системной модернизации банковского сектора Азербайджана были приняты новые законы* :

- Закон Азербайджанской Республики от 16.01.2004 № 590-ІІГ «О банках»;

- Закон Азербайджанской Республики от 10.12.2004 № 802-IIQ «О Центральном банке Азербайджанской Республики» (далее - Закон. № 802-IIQ);

- Закон Азербайджанской Республики от 29.12.2006 № 226 IIIQ «О страховании банковских вкладов» $[3,73]$.

На основе подкрепления принципов, форм и методов банковского развития новыми законами банковской системы была подготовлена благоприятная почва для оптимальной защиты прав и интересов вкладчиков и кредиторов, а также для осуществления банковского контроля на основе Базельских принципов и повышения надежности азербайджанской банковской системы в целом. В результате реализации эффективных мер за вышеуказанный период банковская система азербайджанского государства оказалась устойчивой относительно к экономическим потрясениям различного рода в условиях мирового рынка.

Пока, что в международном контексте азербайджанские банки очень невелики, и каждый из них в отдельности очень незначителен. В отечественной банковской системе страны слиш- ком много небольших банков, объем бизнеса которых не позволяют масштабно реализовать эффект экономии.

\section{Современное состояние банковского сек-} тора

На современном этапе развития банковскую систему Азербайджана (в период с 2005 года по настоящее время) характеризуют как заметные количественные достижения, так и значительные качественные сдвиги. Проводимые в республике за последние годы реформы оказали положительное воздействие на банковскую сферу.

Меры, связанные с реструктуризацией и ужесточением требований, предъявляемых к минимальному капиталу, а также рост коэффициента достаточности капитала следует рассматривать как основные условия укрепления банковской системы и обеспечения эффективности процесса консолидации.

Участие зарубежных инвесторов на уровне структуры собственности банков страны следует рассматривать как важнейший фактор, оказывающий прямое влияние на рост их конкурентоспособности, а также возможность капитализации при таком условии, как либерализация рынка услуг банковской системы.

На период 2020 года в республике в целом по банковской системе средний уровень достаточности капитала (т.е. соотношение собственного капитала согласно активам) составил 18 процентов (минимальный уровень на основе методики Базеле 8 процентов, а по ЦБА 12 процентов).

Центральный банк Азербайджана (ЦБА) в июле 2012 г., в связи реального увеличения капитализация банков принял решение о пятикратном увеличении минимального требования к совокупному капиталу - с 10 до 50 млн. манат. Повышение капитализации позволило банкам улучшить качество предлагаемых услуг и усилило конкуренцию на финансовом рынке. Наряду с увеличением капитальной базы ЦБА ужесточил требования к корпоративному администрированию и риск-управление в банках.

В течение 2016-2017 годов были отозваны лицензии Yunayted Kredit Bank, Bank of Azerbaijan, Gencebank, Texnikabank, Parabank, Zaminbank, Kredobank, Dekabank, Atrabank, Кавказского банка развития, Bank Standard и DəmirBank.

По итогам 31.05.2020 г. в Азербайджане действовали 26 банка, из них 2 государственных,

\footnotetext{
* См подробно об этом: Мамедов 3. Ф, Аббасбейли М.А. Особенности деятельности Центрального Банка Азербайджана // Финансы и кредит. 2013.-47 (575). С. 73-80
} 
24 частных (см таб. № 1).

Банков с зарубежным капиталом -12 . Из них в 7 удельный вес иностранного капитала составляет от 50 до 100\%, в 5 банках - до 50\%, а также действуют 2 местных филиала зарубежных банков (филиал НБ Ирана и Филиал НБ Пакистана).

Кроме того, В Азербайджане функционируют Банка ВТБ* (Азербайджан). Основной задачей банка ВТБ (Азербайджан) является помощь азербайджанскому бизнесу в выходе на новые рынки в странах присутствия группы ВТБ, а также поддержка российских компаний, работающих в Азербайджане. ВТБ (Азербайджан) - основной банк-партнер для азербайджанских предпринимателей, ведущих бизнес с Россией.

Сегодня отношения в банковской сфере между Азербайджаном и Турцией достигли высокого уровня. 2017 г. открытие головного офиса Ziraat Bank *** в Азербайджане внесет вклад в развитие торговли между двумя странами.

Системообразующую значение в отечественной банковской системе по-прежнему занимают -«Международный банк Азербайджана», «PASHA Bank» и «Kapital Bank» - входя в тройку ведущих кредитно-финансовых учреждений страны по величине активов.

В кредитном портфеле банковского сектора свыше 60\% составляют кредиты юридическим лицам, 30\% -потребительские кредиты и 10\% ипотечные кредиты.

На сегодняшний день банковский сектор в основном оценивается по объему адекватного капитала, который в Азербайджане составляет 4,7 миллиарда манатов (в целом по банковскому сектору уровень достаточности капитала составила 18\%). Таким образом, что банковский сектор Азербайджана имеет место надежная обеспеченность активов банков их собственным же капиталом.

Однако, при этом все международные эксперты, «включая МВФ и рейтинговые агентства, полагают, что в Азербайджане все же недостаточная капитализация в банковской системе. Причиной подобного положения можно считать, прежде всего, то, что, во-первых, в Азербайджане качество кредитного портфеля банков с явным перекосом в сторону потребительского кредитования, и во-вторых, еще не повсеместно внедрена система управления рисками и управления ликвидностью. В результате возникает необходимость большей капитализации с целью формирования достаточного высоколиквидного буфера. МВФ рекомендует, финрегулятору Азербайджана решить проблему недокапитализиро-

Таблица 1. Количество банков в Азербайджане

\begin{tabular}{|l|c|c|c|c|c|}
\hline \multicolumn{1}{|c|}{ Показатели } & 31.01 .2020 & 31.02 .2020 & 31.03 .2020 & 31.04 .2020 & 31.05 .2020 \\
\hline Количество банков в Азербайджане & 30 & 30 & 30 & 28 & 26 \\
\hline Государственные банки & 2 & 2 & 2 & 2 & 2 \\
\hline Частные банки & 28 & 28 & 28 & 13 & 12 \\
\hline $\begin{array}{l}\text { Количество банков с иностранным } \\
\text { капиталом: }\end{array}$ & 14 & 14 & 7 & 7 & 7 \\
\hline $\begin{array}{l}\text { в том числе с уставным капиталом } \\
\text { от 50\% до 100\% }\end{array}$ & 7 & 7 & 7 & 2 & 2 \\
\hline $\begin{array}{l}\text { Количество банков, у которых } \\
\text { отозвана лицензия }\end{array}$ & 0 & 0 & 0 & 2 \\
\hline
\end{tabular}

Источник: Годовые отчеты ЦБ Азербайджана

\footnotetext{
* Официальное открытие Банка ВТБ (Азербайджан) состоялось 23 ноября 2009 г. (лицензия № 162). Акционерный капитал ОАО Банк ВТБ (Азербайджан) распределен следующим образом: Банк ВТБ (ПАО) - 99,9999\%; Физическое лицо - 0,0001\%. Банк ВТБ (Азербайджан) - часть международной финансовой группы ВТБ, имеющая представительства в более чем 20 странах мира. Основным акционером ВТБ является Российская Федерация с долей в 60,9\%. Деятельность банка охватывает такие страны, СНГ, а также Грузию Кипр, Австрию, Францию, Германию, Китай и Индию. https://ru.vtb.az/about/

* Банк Ziraat - один из самых крупных в Турции, основан в 1863 году, принадлежит государству. Имеет сеть из более 1,4 тыс. филиалов по стране имеет сеть из более 1,4 тыс. филиалов по стране Ziraat Bank» имеется 195 отделений и филиалов в 18 странах мира: За пределами Турции «дочки» банка действуют в Германии, Боснии и Герцеговине, России, Казахстане, Туркменистане и Узбекистане. Также Ziraat Bank имеет представительства в Великобритании, США, Болгарии, Грузии, Ираке, на Северном Кипре, в Греции, Саудовской Аравии и Иране.
} 
ванных банков» [4].

Представляется очевидным, что на современном этапе исторического развития азербайджанская экономика испытывает необходимость в эффективности и капитализированности банковской системы, особенно в отношении присоединения к ВТО.

В плане достижения данной стратегической цели необходимо не только проводить грамотную политику, направленную на формирование условий с целью поддержки финансовой системы государством, но и повысить уровень капитализация банковской системы Азербайджана за счет различных кредитных организаций.

Одной из важнейших проблем, обеспечивающих совершенствование банковской системы республики, является рост конкурентоспособности банков в процессе их постепенного слияния и увеличение банковского капитала.

Проф. Мамедов 3.Ф., считает, что одним«из оптимальных путей роста капитализации является первичность размещения акций (IPO). Следовательно, капитализация банковской системы, публичный или корпоративный характер акционерных обществ представляет собой целый комплекс проблем, решение которых основная необходимость для Азербайджана перед вступлением в ВТО. Это в свою очередь, дает возможность увеличить рост капитала банков до $60 \% »[5,96]$.

Представляется очевидным, что наращивание капитализации банков обеспечивается благодаря выходу на рынок IPO. К сожалению, приходится акцентировать внимание на то, что подавляющим большинством банков рынок ценных бумаг не рассматривается в качестве механизма по привлечению ресурсов.

Таким образом, основополагающие цели будущего развития банковской системы Азербайджана заключаются в повышении стабильности банков, распространении мировых стандартов корпоративного управления в банках, роста доверия инвесторов, вкладчиков и кредиторов к банковской системе, что в свою очередь должно достигаться путем защиты их прав, усилении качества и, разумеется, прозрачности деятельности банковских учреждений.

Эффективность и стабильность развития отечественных банковских учреждений должно быть основано на внедрении соответствующих мер на уровне деятельности как Центрального банка Азербайджана, так и отдельных банков.

Формирование и развитие исламского банкинга в Азербайджане

Одной из основных качественных тенденций в банковской системе является рост уровня микрокредитования. Основными его преимуществами являются высокий уровень прибыли, наименьший риск, масштабность охвата экономики как с точки зрения географии так и клиентской базы. Основное макроэкономическое значение микрокредитования заключается в том, что оно способствует росту занятости населения, в частности, в сельской местности. Рост уровня микрокредитования увеличивает интерес к исламскому банкингу на мировом уровне.

Отрасль исламских финансов является одной из самых быстрорастущих в мире: за последние 10 лет годовые темпы роста активов составляют 15-20\%. «По прогнозам, к 2020 г. объем исламской финансовой индустрии достигнет 1,8 трлн. долл. США» [6, 6].

Исламская банкинг предлагает вариант, обеспечивающий серьезную стабильность в финансировании всех проектов на международном уровне.

Следует учесть, что благодаря исламской банковской системе обеспечивается более высокий уровень стабильности в плане финансирования всех проектов на международном уровне.

Со стороны Азербайджана предпринимаются важные шаги для сотрудничества с Исламским Банком Развития* (IDB), при этом большая роль отводится внедрению исламского банка в Азербайджане.

«Группа ИБР вовлечена в широкий спектр деятельности:

- проектное финансирование;

- содействие снижению уровня бедности в странах членах;

- развитие торгово-экономического сотрудничества стран-членов;

- поддержка малого и среднего предпринимательства;

- мобилизация ресурсов стран-членов;

- участие в капитале исламских финансовых институтов;

- страхование и перестрахование инвестиций и экспортного кредитования;

- организация исследований и образовательных программ для трудоспособного населения стран-членов;

* В настоящее время участниками ИБР являются 56 государств. 
- оказание помощи странам-членам в чрезвычайных ситуациях;

- другие аспекты деятельности» [7,178].

В настоящее время в республике учреждена единственная совместная компания с IDB Caspian International Investment Company (Азербайджанская инвестиционная компания 25\% и IDB 75\%). Цели данной компании подчинены обеспечению притока инвестиций в республику и выходу азербайджанских компаний на мировой рынок.

Правительство Азербайджана и Исламский банк развития* подписали грантовое соглашение, предусматривающее предоставление технической помощи в целях подготовки законодательной базы, касающейся исламского финансирования. Соглашение ставит целью исследование банковского законодательства и анализ возможностей внедрения в Азербайджане основных норм исламского банкинга.

Для подготовки предложений по развитию исламского финансирования в Азербайджане привлечен консорциум компаний Ekvita Consulting и европейские эксперты**. Ответственным за реализацию проекта технического содействия подготовке правовой базы по исламскому финансированию в Азербайджане назначено Агентство по развитию малого и среднего бизнеса (КОВІ̇А) при министерстве экономики страны. Безусловно, законодательное регулирование исламского финансирования создаст новые возможности банкам и компаниям, оказывающим исламские услуги в республике, и будет содействовать привлечению в Азербайджан исламских инвесторов.

Однако, как отмечают специалисты Moodys в отчете о перспективах развития исламского банкинга в странах СНГ, что «Несмотря на большое количество мусульманского населения, перспективы развития исламского банкинга в Азербайджане являются слабыми» [8].

На наш взгляд, проблему внедрения исламского банкинга необходимо тщательно исследовать, что связано с решением двух вопросов созданием фундаментальной законодательной базы и подготовкой профессиональных кадров, последнее особенно важно в целях эффективности самого процесса. Решение проблемы, обу- славливающее высокий уровень эффективности банковской системы Азербайджана, заключается в росте конкурентоспособности банковских учреждение на базе их слияния и увеличения банковского капитала.

\section{Заключение}

Итак, Объективная необходимость комплексной модернизации банковской системы Азербайджана обусловила принятие новых законов после 2004 г. Представляется очевидным, что на современном этапе исторического развития азербайджанская экономика испытывает необходимость в эффективности и капитализированности банковской системы, особенно в отношении присоединения к ВТО.

Таким образом, основополагающие цели будущего развития банковской системы Азербайджана заключаются в повышении стабильности банков, распространении мировых стандартов корпоративного управления в банках, роста доверия инвесторов, вкладчиков и кредиторов к банковской системе, что в свою очередь должно достигаться путем защиты их прав, усилении качества и, разумеется, прозрачности деятельности банковских учреждений.

Одной из основных качественных тенденций в банковской системе является рост уровня микрокредитования. Рост уровня микрокредитования увеличивает интерес к исламскому банкингу на мировом уровне. Со стороны Азербайджана предпринимаются важные шаги для сотрудничества с Исламским Банком Развития, при этом большая роль отводится внедрению исламского банка в Азербайджане.

На наш взгляд, проблему внедрения исламского банкинга необходимо тщательно исследовать, что связано с решением двух вопросов созданием фундаментальной законодательной базы и подготовкой профессиональных кадров, последнее особенно важно в целях эффективности самого процесса.

Итак, решение проблемы, обуславливающее высокий уровень эффективности банковской системы Азербайджана, заключается в росте конкурентоспособности банковских учреждение на базе их слияния и увеличения банковского капитала.

\footnotetext{
* В 1991-2018гг Исламский банк развития выделил Азербайджану кредитов на сумму \$1,387 млрд. Отметим, что на подготовку правовой базы для исламского финансирования

** Исламский банк развития (ИБР) предоставил Азербайджану техническую помощь в размере 200 тысяч долларов. Техническую помощь предусматривает анализ банковского законодательства и изучение возможностей внедрения в Азербайджане принципов исламского банкинга.
} 


\section{Библиографический список}

1. Мамедов 3. Ф. Основные тенденции развития денежно-кредитной системы Азербайджана /// Финансы и кредит. - 20084 (292). 66-79

2. Мамедов 3. Ф., Зейналов В., Ибиш Дж, Шашина Н.С. Антикризисная политика в банковской сфере Российской федерации, Азербайджана и Турции: сравнительный анализ// Журнал - «Экономика и Управление». N 9 (59) 2010. 3-12

3. Мамедов 3. Ф, Аббасбейли М. А. Особенности деятельности Центрального Банка Азербайджана // Финансы и кредит. 2013. - 47 (575). С. 73-80

4. МВФ рекомендует финрегулятору Азербайджана решить проблему недокапитализированных банков// https://interfax.az/view/778620. 23.09.2019

5. Мамедов 3.Ф. Денежно-кредитная система Азербайджана// Журнал -« Общество и Экономика».- 2009. № 3.- 82-106

6. Мамедов 3. Ф. Исламская банковская система: новые вызовы, проблемы и перспективы развития. Журнал: Экономика и Управление.- 2018;(4):4-10. Издательство: Санкт-Петербургский университет технологий управления и экономики (Санкт-Петербург).

7. Мамедов 3. Ф. Исламский банк развития - как главная финансовая организация исламского мира // Журнал: Информационные Технологии и Системы: Управление, Экономика, Транспорт, Право. 2019._ 2 (34). Страницы: $175-179$

8. Moodys отмечает слабые перспективы развития исламского банкинга в Азербайджане // http://interfax.az/ view/774919. 15.08.2019 